\title{
Bioanalysis
}

\section{Stable isotopes and LC-MS for monitoring metabolic disturbances in Friedreich's ataxia platelets}

Background: Friedreich's ataxia (FRDA) is an autosomal recessive disease with metabolic abnormalities that have been proposed to play an important role in the resulting neurodegeneration and cardiomyopathy. The inability to access the highly affected neuronal and cardiac tissues has hampered metabolic evaluation and biomarker development. Methods: Employment of a LC-MS-based method to determine whether platelets isolated from patients with FRDA exhibit differentiable metabolism compared with healthy controls. Results: Isotopologue analysis showed a marked decrease in glucose incorporation with a concomitant increase in palmitatederived acyl-CoA thioesters in FRDA platelets compared with controls. Conclusion: Our findings demonstrate that platelets can be used as a surrogate tissue for in vivo biomarker studies to monitor new therapeutic approaches for the treatment of FRDA.

Friedreich's ataxia (FRDA) affects one in 29,000 Caucasians making it the most frequently inherited ataxia [1]. It is an autosomal recessive genetic disorder, with a mean $\pm \mathrm{SD}$ age at onset of $10 \pm 7.4$ years, and no known effective treatment [2]. The most affected tissues in FRDA are the heart, dorsal root ganglia, posterior columns of the spinal cord and the corticospinal tracts $[1,3]$. Most FRDA individuals develop dysarthria and are wheelchairbound by $15.5 \pm 7.4$ years (mean age \pm SD) after onset of the disease [1]. The genetic basis of most FRDA cases involves a nucleotide expansion in the FXN gene due to triplicate guanine-adenine-adenine (GAA) repeats in intron 1 [4]. This leads to a deficiency in the protein frataxin, which is thought to be involved in assembling iron-sulfur protein clusters [5]. A small minority of FRDA cases $(\sim 1-3 \%)$ carry a compound heterozygous GAA expansion on one allele of the frataxin gene with a point mutation or deletion on the other allele $[1,6]$. All of the mutations that have been discovered so far are in the 81-210 region of frataxin (L101S; D122Y; G130V; I40F; R165C; W173G; L182F; L198R) [7-11]. The mature biologically active form of frataxin arises from mitochondrial processing of the $23.1 \mathrm{kDa}$ precursor
(1-210) frataxin. Transfer of the precursor (1-210) frataxin from the cytosol into the mitochondria is facilitated by a mitochondrial targeting sequence, which is present at amino acids 1-20. Processing then occurs through an initial cleavage at glycine- 41 by MPP, which removes the targeting sequence [12]. The resulting intermediate $18.8 \mathrm{kDa}(42-201)$ frataxin is then cleaved by MPP at lysine- 80 to give the 14.3 KDa mature (81-210) frataxin [13]. This means that the missense mutations in frataxin (101-198 region) do not prevent mitochondrial targeting. However, the mutations result in complex biochemical consequences that play a role in determining the severity of FRDA [14-16]. In contrast, the intronic triplet GAA repeats on both alleles of the $F X N$ gene that occurs in most FRDA patients results in silencing of the gene together with significantly reduced expression of frataxin protein that has no missense mutations.

A range of cellular processes depend on iron-sulfur clusters for proper biological functions [17], such as the electron-transferring components of the mitochondrial electron transport chain and the Krebs cycle enzyme aconitase [18]. Frataxin localization to the mitochondria suggests that altered
Andrew J Worth ${ }^{1,2,3}$, Sankha S Basu $^{1,3}$, Eric C Deutsch ${ }^{3,4}$, Wei-Ting Hwang ${ }^{2,5}$, Nathaniel W Snyder ${ }^{1,6}$, David R Lynch ${ }^{4}$ \& Ian A Blair*,1,2,3

${ }^{1}$ Center of Excellence in Environmental Toxicology, University of Pennsylvania, Philadelphia, PA 19104, USA

2Penn SRP Center, University of Pennsylvania, Philadelphia, PA 19104, USA ${ }^{3}$ Department of Systems Pharmacology \& Translational Therapeutics, Perelman School of Medicine, University of Pennsylvania, Philadelphia, PA 19104, USA ${ }^{4}$ Departments of Neurology \& Pediatrics, The Children's Hospital of Philadelphia \& the Perelman School of Medicine, University of Pennsylvania, Philadelphia, PA 19104, USA

${ }^{5}$ Department of Biostatistics

\& Epidemiology, Perelman School of Medicine, University of Pennsylvania, Philadelphia, PA 19104, USA

${ }^{6}$ AJ Drexel Autism Institute, Drexel University, Philadelphia, PA 19104, USA

*Author for correspondence:

Tel.: +1 2155739885

Fax: +1 2155739889

ianblair@mail.med.upenn.edu 


\section{Key terms}

Friedreich's ataxia: The genetic basis of $98 \%$ of

Friedreich's ataxia cases involves a nucleotide expansion in

the FXN gene due to triplicate GAA repeats in intron 1. The

remaining cases arise from point mutations in the FXN gene.

Frataxin: Human frataxin is a $23 \mathrm{kDa}$ protein that is synthesized on ribosomes in the cytoplasm. It has a mitochondrial targeting sequence, which is converted to the mature $14 \mathrm{kDa}$ protein by a protease in the mitochondrial matrix. Frataxin is required for iron-sulfur protein cluster protein assembly (such as aconitase) in the mitochondria.

Platelets: Blood cells that are released from megakaryocytes which play an important role in hemostasis. In this study, human platelets were utilized in an ex vivo assay for studying metabolism as a surrogate for tissues that were not accessible.

Isotopologues: Identical molecules that have different isotopic compositions such as ${ }^{13} \mathrm{CH}_{2} \mathrm{CH}_{2} \mathrm{CH}_{3},{ }^{13} \mathrm{CH}_{2}{ }^{13} \mathrm{CH}_{2} \mathrm{CH}_{3}$ and ${ }^{13} \mathrm{CH}_{2}{ }^{13} \mathrm{CH}_{2}{ }^{13} \mathrm{CH}_{3}$ isotopologues.

CoA: An intracellular thiol derived from cysteamine, pantothenate and adenosine triphosphate that is found in both eukaryotes and prokaryotes. CoA forms thioester derivatives with short, medium or long chain fatty acids, which are involved in numerous metabolic processes such as acetylation of histone proteins.

mitochondrial function plays a role in FRDA [19,20]. Previous studies utilized antioxidants in an attempt to improve mitochondrial function [21,22]; however, in addition to antioxidants, it seems likely that supplementation of highly consumed metabolic precursors could have a positive synergistic effect [23]. Therefore, further characterization of metabolic abnormalities associated with FRDA could reveal additional therapeutic targets in this poorly understood disease.

LC-SRM/MS offers a highly sensitive and specific platform for performing metabolic studies in human platelets [24]. While absolute quantification of metabolites provides insight into the metabolic state of a system [25], it is possible for compensatory metabolic actions to occur that maintain a metabolite pool by altering the utilization of other precursors [26,27]. Thereby, shifts in metabolism might go unnoticed with absolute quantification as the only indicator of the metabolic state of a system. For this reason it is important to assess the utilization of metabolic precursors [28]. Isotopologue analysis enables evaluation of metabolic pathway activity, as isotopic labeling of a metabolite pool reveals the relative contribution of specific enzymes and pathways [29].

We have recently shown that isolated human platelets can serve as a platform for metabolic studies [24]. Platelets have been used previously to assess the activity of serotonin selective reuptake inhibitors [30] as well as a model for assaying glutamate uptake in Parkinson's disease [31]. Several studies have also used platelets to assay the activity of the electron transport chain in multiple neurological diseases [32]. In addition to the benefit of a relatively noninvasive sample collection and isolation, platelets are mitochondria-rich and maintain metabolic activity if properly isolated $[24,33]$. Since inherited metabolic diseases often affect metabolism globally, we reasoned that platelets could serve as a surrogate diagnostic tissue for inherited metabolic diseases such as FRDA if these pathways are utilized in platelets. Furthermore, isolated platelets allow for more complex metabolic challenges than are possible in other in vivo assays [24].

Here, we have tested two isotopic tracers $\left(\left[{ }^{13} \mathrm{C}_{6}\right]\right.$-glucose and $\left[{ }^{13} \mathrm{C}_{16}\right]$-palmitate) that indicate metabolic variations in FRDA platelets by analysis of isotopic enrichment in various acyl-CoA thioesters spanning multiple metabolic pathways using methodology that was validated in normal volunteers (Figure 1) [24]. Glycolysis results in the incorporation of $\left[{ }^{13} \mathrm{C}_{6}\right]$-glucose directly into Krebs cycle metabolites through its conversion to $\left[{ }^{13} \mathrm{C}_{2}\right]$-acetyl-CoA, which then proceeds through the Krebs cycle (Figure 2). Conversely, $\left[{ }^{13} \mathrm{C}_{16}\right]$-palmitate is converted primarily into acetyl-CoA, $\beta$-hydroxybutyryl (HB)-CoA and 3-hydroxy-3-methylglutaryl (HMG)-CoA during short-term incubations in platelets (Figure 2). We report the use of isotopologue analysis for the characterization of $\left[{ }^{13} \mathrm{C}_{6}\right]$-glucose and $\left[{ }^{13} \mathrm{C}_{16}\right]$-palmitate incorporation into acyl-CoA thioesters in the platelets of patients with FRDA, unaffected controls and the utility of this methodology as a biomarker of disease severity for FRDA. Furthermore, we propose this system as a potential model for tracking therapeutic response in FRDA.

\section{Patients \& methods}

\section{Participants}

Ten FRDA patients and ten controls were entered into the study. There were no significant differences between the two groups in their mean ages $(32.0 \pm$ 7.8 [SD] for FRDA, $31.4 \pm 10.3$ [SD] for control) nor the mean \pm SD GAA repeat length among patients $(476 \pm 149.8)$. The GAA repeat lengths indicated that the FRDA was of moderate severity (Table 1). Blood samples were obtained from the participants who were enrolled in an ongoing Friedreich's Ataxia Research Alliance study at the Children's Hospital of Philadelphia (IRB \# 01-002609).

\section{Reagents}

Glucose, $\left[{ }^{13} \mathrm{C}_{6}\right]$-glucose, sodium chloride $(\mathrm{NaCl})$, potassium chloride $(\mathrm{KCl})$, sodium bicarbonate $\left(\mathrm{NaHCO}_{3}\right)$, calcium chloride $\left(\mathrm{CaCl}_{2}\right)$, magnesium chloride $\left(\mathrm{MgCl}_{2}\right)$, 5-sulfosalicylic acid (SSA), ammonium acetate and trichloroacetic acid (TCA) were purchased from Sigma-Aldrich (MO, USA). $\left[{ }^{13} \mathrm{C}_{16}\right]$-palmitate was purchased from Cambridge Isotope Laboratories, Inc. 
(MA, USA). Acid-citrate-dextrose Vacutainer ${ }^{\circledR}$ tubes (8.5 ml; Sol A) were purchased from BD Biosciences (NJ, USA). All solvents for LC-MS were Optima grade purchased from Fisher Scientific (PA, USA).

\section{Platelet isolation \& treatment}

Whole blood was drawn into $8.5 \mathrm{ml}$ acid-citrate-dextrose Vacutainer tubes, transferred to $15-\mathrm{ml}$ polypropylene tubes and spun at $175 \times g$ for 15 min with no brakes as described previously [24]. The upper plateletrich layer was then transferred to a new tube and spun at $400 \times g$ for $10 \mathrm{~min}$. The resulting platelet pellet was resuspended in $1 \mathrm{ml}$ prewarmed Tyrode's solution $(139 \mathrm{mM} \mathrm{NaCl}, 3 \mathrm{mM} \mathrm{KCl}, 17 \mathrm{mM} \mathrm{NaHCO}$, $3 \mathrm{mM} \mathrm{CaCl}_{2}$ and $1 \mathrm{mM} \mathrm{MgCl}_{2}$ ) at $37^{\circ} \mathrm{C}$ containing $5 \mathrm{mM}\left[{ }^{13} \mathrm{C}_{6}\right]$-glucose or $5 \mathrm{mM}$ glucose with $100 \mu \mathrm{M}$ $\left[{ }^{13} \mathrm{C}_{16}\right]$-palmitate and transferred to a $1.5 \mathrm{ml}$ microcentrifuge tube. Samples used for isotopic correction were treated with Tyrode's containing only $5 \mathrm{mM}$ glucose. Suspended platelets were incubated with tracers for $1 \mathrm{~h}$ at $37^{\circ} \mathrm{C}$ prior to quenching and acyl-CoA extraction.

\section{Acyl-CoA extraction}

The extraction and LC-MS analysis have been described in detail previously [24,34]. Briefly, treated platelets were pelleted by centrifugation at $1000 \mathrm{x} g$ for $2 \mathrm{~min}$ and resuspended in $1 \mathrm{ml}$ of ice-cold $10 \%$ TCA followed by pulse-sonication for $30 \mathrm{~s}$ on ice using a sonic dismembranator (Fisher, MA, USA), followed by a 10 min centrifugation at $15,000 \times g$. The supernatant was transferred to a fresh tube, and the pellet was discarded. The supernatant was purified by SPE as follows: Oasis HLB $1 \mathrm{~cm}^{3}(30 \mathrm{mg}) \mathrm{SPE}$ columns (Waters, MA, USA) were conditioned with $1 \mathrm{ml}$ of methanol followed by $1 \mathrm{ml}$ of water. The collected supernatant was applied, washed with $1 \mathrm{ml}$ of water and finally eluted using three subsequent applications of $0.5 \mathrm{ml}$ of methanol containing $25 \mathrm{mM}$ ammonium acetate. Eluted compounds were evaporated to dryness under nitrogen and resuspended in $50 \mu \mathrm{l}$ of $5 \%$ SSA in water. Injections of $20 \mu \mathrm{l}$ were made for LC-MS/MS analysis.

\section{LC-MS}

Acyl-CoAs were separated using a reversed-phase HPLC (Phenomenex, CA, USA) Luna C18 column $(2.0 \times$ $150 \mathrm{~mm}$, particle size $5 \mu \mathrm{m}$ ) with $5 \mathrm{mM}$ ammonium acetate in water as solvent $\mathrm{A}, 5 \mathrm{mM}$ ammonium acetate in 95:5 ACN/water $(\mathrm{v} / \mathrm{v})$ as solvent $\mathrm{B}$ and 80:20:0.1 ( $\mathrm{v} / \mathrm{v} / \mathrm{v}) \mathrm{ACN} /$ water/formic acid as solvent $\mathrm{C}$ as previously described [24,27]. Gradient conditions were as follows: $2 \%$ $\mathrm{B}$ for $1.5 \mathrm{~min}$, increased to $25 \%$ B over $3.5 \mathrm{~min}$, increased to $100 \% \mathrm{~B}$ in $0.5 \mathrm{~min}$ and held for $8.5 \mathrm{~min}$, washed with $100 \% \mathrm{C}$ for $5 \mathrm{~min}$, before equilibration for $5 \mathrm{~min}$. The

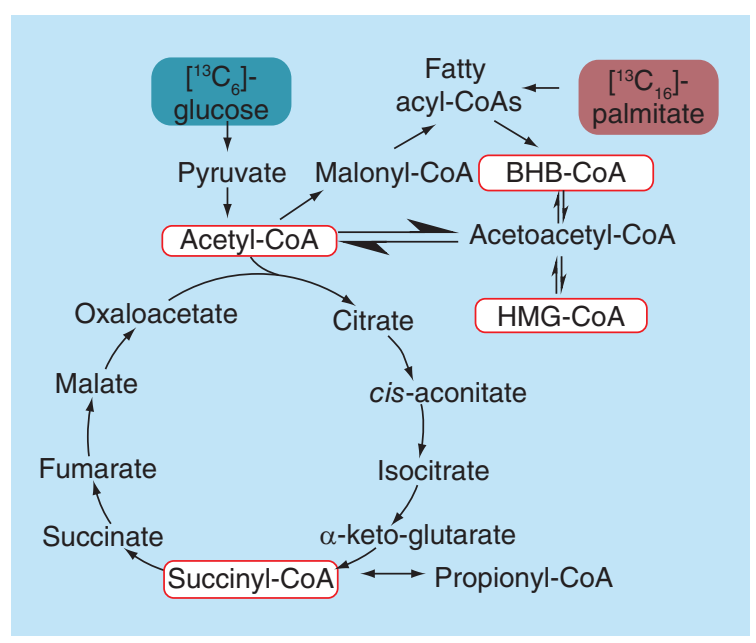

Figure 1. Metabolic incorporation of $\left[{ }^{13} \mathrm{C}_{6}\right]$-glucose and $\left[{ }^{13} \mathrm{C}_{16}\right]$-palmitate isotopic tracers into acyl-CoA thioesters. HMG: 3-hydroxy-3-methylglutaryl,

$\beta \mathrm{HB}: \beta$-hydroxybutyryl.

flow rate was $200 \mu \mathrm{l} / \mathrm{min}$. Samples were analyzed using an API 4000 triple-quadrupole mass spectrometer (AB SCIEX, MA, USA) in the positive electrospray (ESI) mode. Samples $(20 \mu \mathrm{l})$ were injected using a Leap CTC autosampler (CTC Analytics, Zwingen, Switzerland) where they were maintained at $4^{\circ} \mathrm{C}$, and data were analyzed with Analyst 1.4.1 software. The column effluent

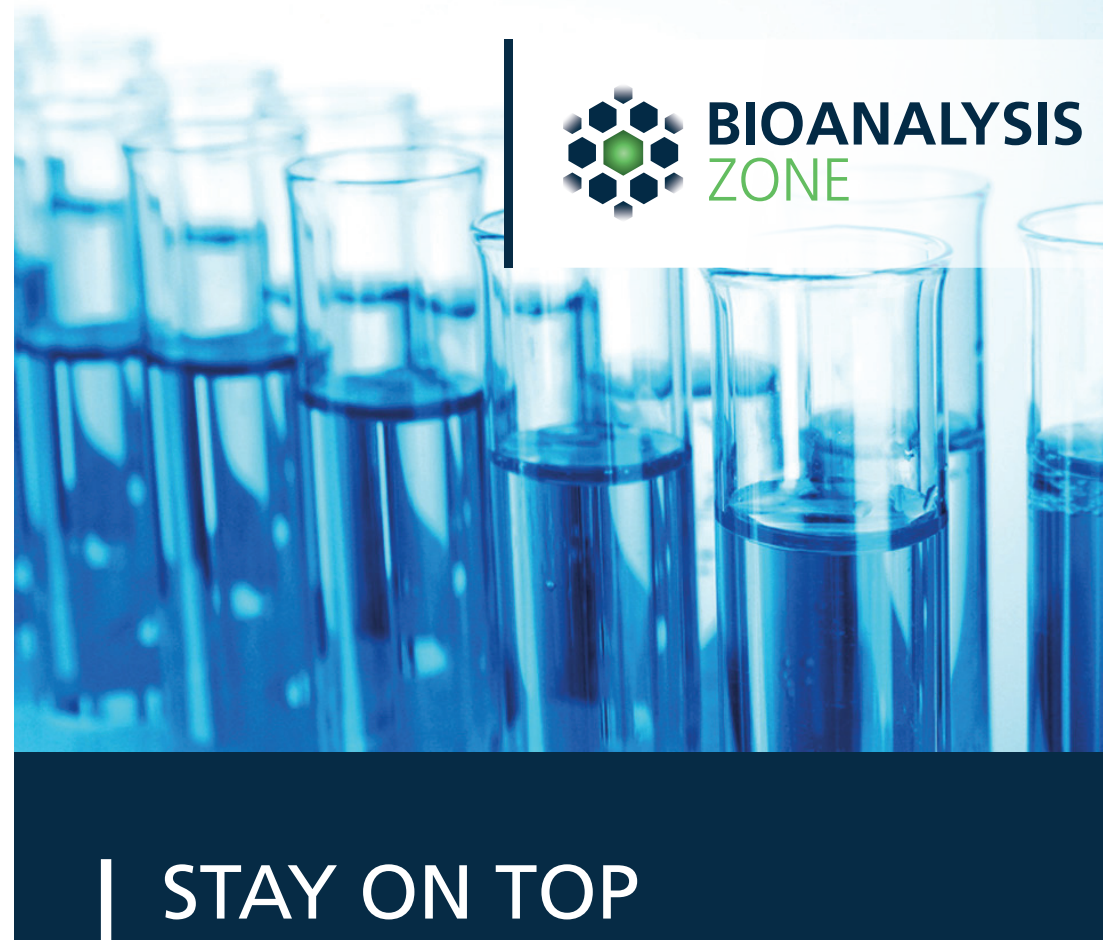

Exclusive access to news, articles and videos

Join today

www.Bioanalysis-Zone.com 


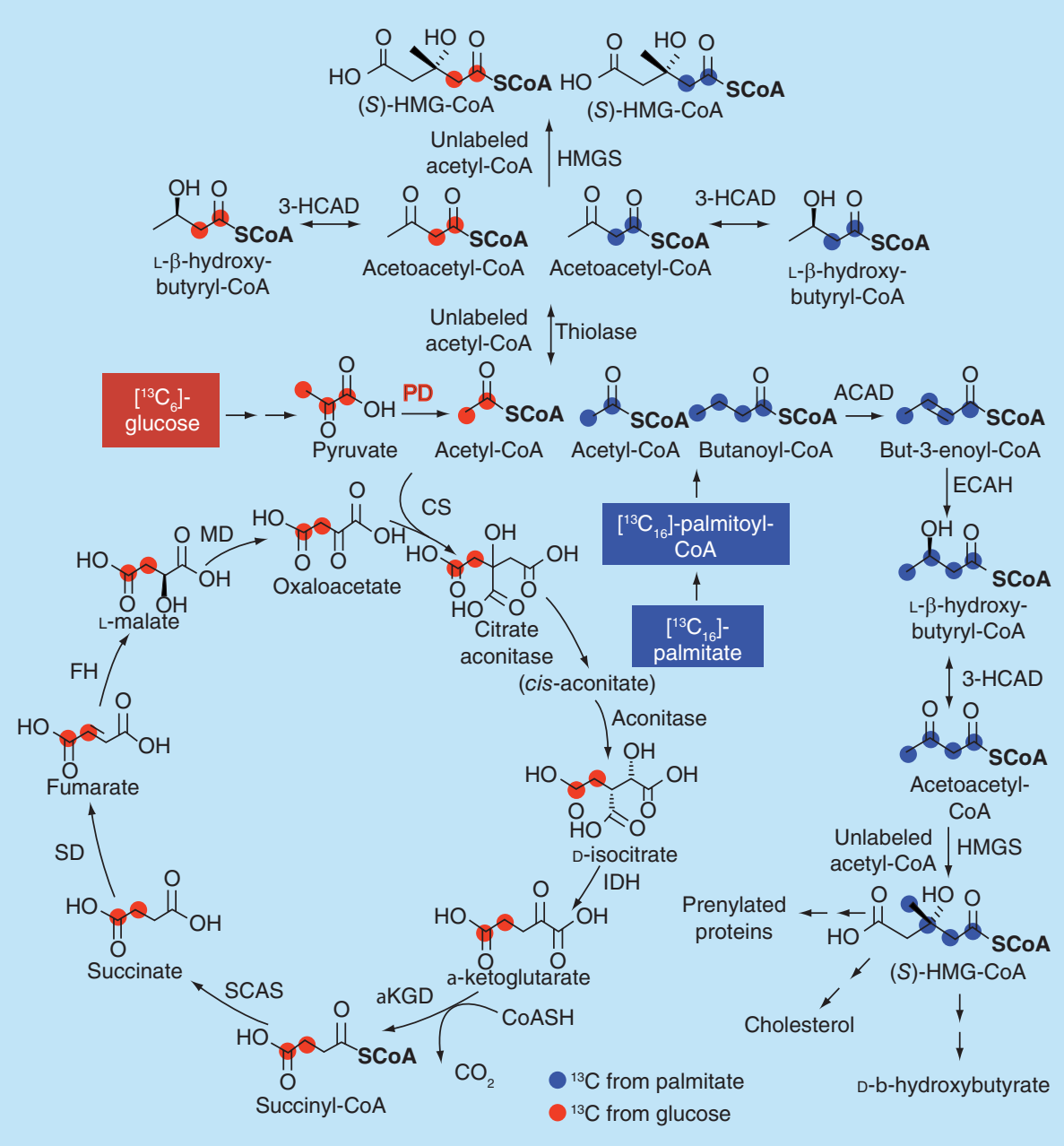

Figure 2. Formation of acyl-CoA thioester isotopologues from $\left[{ }^{13} \mathrm{C}_{6}\right]$-glucose and $\left[{ }^{13} \mathrm{C}_{16}\right]$-palmitate through one turn of the cycle.

was diverted to the mass spectrometer from 8 to $18 \mathrm{~min}$ and to waste for the remainder of the run. The mass spectrometer operating conditions were as follows: ion spray voltage $(5.0 \mathrm{kV})$, nitrogen as curtain gas (15 units), ion source gas 1 (eight units), gas 2 (15 units) and collisioninduced dissociation (CID) gas (five units). The ESI probe temperature was $450^{\circ} \mathrm{C}$, the declustering potential was $105 \mathrm{~V}$, the entrance potential was $10 \mathrm{~V}$, the collision energy was $45 \mathrm{eV}$ and the collision exit potential was $15 \mathrm{~V}$ for all analytes reported. The LC-SRM/MS transitions that were used are shown in Supplementary Table 1 and typical chromatograms showing separation of the acylCoAs and their isotopologues is shown in Figure 3. Peak areas of all isotopologues where $\left[{ }^{13} \mathrm{C}\right]$-labeling of the acyl moiety is possible were utilized to determine the percentage isotopic enrichments, which are reflective of incorporation into downstream metabolites. Label-free cells were used to generate an isotopologue-enrichment matrix (also called a correction matrix) for acetyl-CoA, succinyl$\mathrm{CoA}, \beta \mathrm{HB}-\mathrm{Co} A$ and HMG-CoA. An isotopologue array generated for each sample was multiplied by the inverse of the correction matrix determined experimentally from the label-free cells to determine the absolute enrichment of each isotopologue as described by Fernandez et al. [35]. This approach reduces the underestimation of isotopic labeling in highly labeled substrates and is amenable to a correction matrix generated from label-free experimental controls as were used in this study. It also addresses the issue of errors that could arise from analysis of isotopologues with low S/Ns. This is because the label free control will contain the lowest signal for peaks derived from natural isotopic abundance and thus it is possible to estimate the LOQ for the lowest abundance isotopologue of interest $[36] .\left[{ }^{13} \mathrm{C}\right]$-incorporation has been presented as a percentage of the unlabeled isotopologue for each acyl-CoA that was analyzed (Figures 4 \& 5).

\section{Statistical analysis}

Descriptive statistics were calculated. Unless otherwise specified, data have been expressed as means $\pm \mathrm{SD}$. 
Normality of the data was examined by Shapiro-Wilk $\mathrm{W}$ test. Comparison of the labeling between patients with FRDA and unaffected controls were made by a two sample $t$-test with equal variance assumption (or unequal variance when appropriate). All tests were two-sided. To evaluate the combination of $\mathrm{M}+2$ labeling from $\left[{ }^{13} \mathrm{C}_{6}\right]$-glucose for acetyl-CoA and $\mathrm{M}$ +2 labeling from $\left[{ }^{13} \mathrm{C}_{16}\right]$-palmitate for $\beta \mathrm{HB}-\mathrm{CoA}$, a logistic regression analysis was performed. Sensitivity and specificity were computed at each possible cut-off value based on the predictive score estimated from the logistic model, and a receiver operating characteristic (ROC) curve was generated. The area under the ROC curve was computed to measure the ability of the combined biomarkers in correctly classifying those with and without FRDA. A higher AUC value for the ROC indicated better discrimination. Statistical analyses were conducted using GraphPad Prism v 6.0 for Mac OS X and STATA v13.0 for Windows.

\section{Results}

\section{Glucose labeling}

There was extensive labeling in the isotopologue of acetyl-CoA $2 \mathrm{Da}$ higher in mass $(\mathrm{M}+2)$ than the endogenous acetyl-CoA $(M+0)$ in platelets treated with $\left[{ }^{13} \mathrm{C}_{6}\right]$-glucose $(5 \mathrm{mM})$ that were obtained from both FRDA and unaffected controls (Figure 4A). This resulted from the action of pyruvate dehydrogenase on pyruvate derived from $\left[{ }^{13} \mathrm{C}_{6}\right]$-glucose (Figure 2). FRDA platelets exhibited significantly reduced $\mathrm{M}+2$ labeling in acetyl-CoA (mean \pm SD: $7.0 \pm 3.9 \%$; $p<0.05)$ when compared with acetyl-CoA labeling $(12.3 \pm 5.5 \%)$ in control platelets (Figure 4A \& E). This finding is consistent with decreased utilization of $\left[{ }^{13} \mathrm{C}_{6}\right]$-glucose for the pyruvate dehydrogenase-mediated formation of acetyl-CoA (Figure 2). The FRDA platelets also showed decreased $\mathrm{M}+2$ labeling of succinyl-CoA $(6.3 \pm 6.1 \%$; $\mathrm{p}<0.05)$ when compared with control platelets $(10.8$ $\pm 2.3 \%$ ) (Figure $4 \mathrm{~B} \& \mathrm{E}$ ). These levels of incorporation were very similar to those observed for acetyl-CoA (Figure 4A) as might be expected from its role as a Krebs cycle intermediate (Figure 2). The formation of $\beta \mathrm{HB}-\mathrm{CoA}$ and HMG-CoA can arise through two different pathways. The first pathway involves thiolasemediated formation of acetoacetyl-CoA followed by the 3-hydroxy-CoA dehydrogenase-mediated metabolism of acetoacetyl-CoA to $\beta \mathrm{HB}-\mathrm{CoA}$ or HMG-CoA synthase-mediated metabolism of acetoacetyl-CoA to HMG-CoA (Figure 2). The second pathway, which we recently demonstrated to occur in neuronal cells [27], involves conversion of palmitate to butyryl-CoA, which is then further metabolized to $\beta \mathrm{HB}-\mathrm{CoA}$ and HMG-CoA (Figure 2). The first pathway should lead to the formation of $\mathrm{M}+2$ isotopologues of $\beta \mathrm{HB}$ $\mathrm{CoA}$ and HMG-CoA from $\left[{ }^{13} \mathrm{C}_{6}\right]$-glucose; whereas the second pathway should only be observed in these short-term incubations through the formation of $\mathrm{M}+$ 4 isotopologues from the metabolism of $\left[{ }^{13} \mathrm{C}\right]$-labeled palmitate (Figure 2). In keeping with these concepts, both $\beta \mathrm{HB}-\mathrm{CoA}$ and HMG-CoA exhibited substantial labeling in their $\mathrm{M}+2$ isotopologues after a $1 \mathrm{~h}$ incubation with $\left[{ }^{13} \mathrm{C}_{6}\right]$-glucose (Figure $4 \mathrm{C} \& \mathrm{D}$ ). The $\mathrm{M}+2$ labeling of HMG-CoA in both FRDA $(10.3 \pm 7.3 \%)$ and control $(16.7 \pm 4.8 \%)$ platelets (Figure $4 \mathrm{D})$ was significantly higher than that observed for acetyl-CoA in FRDA $(7.0 \pm 3.9 \%)$ and control $(12.3 \pm 5.5 \%)$ platelets (Figure 4A). This suggested that the HMG-CoA pool size was smaller than the other analytes and so

Table 1. Characteristics of subjects who donated platelets for the study together with platelet isotopologue incorporation.

\begin{tabular}{|lllllll|}
\hline Labeled precursor & Variable & Controls & SD & FRDA patients & SD & p-value \\
& Subjects enrolled & 10 & NA & 10 & NA & NA \\
\hline & Male (\%) & 60 & NA & 40 & NA & NA \\
\hline & Mean age & 31.4 & 10.3 & 32 & 7.8 & 0.880 \\
& Mean GAA repeat length & $<30$ & NA & 476 & 150 & $<0.001$ \\
\hline & Acetyl-CoA M+2 (\%) & 12.3 & 5.5 & 7.0 & 3.9 & 0.020 \\
& Succinyl-CoA M+2 (\%) & 10.8 & 2.3 & 6.3 & 6.1 & 0.040 \\
& $\beta$ HB-CoA M+2 (\%) & 8.5 & 2.9 & 5.1 & 2.4 & 0.010 \\
& HMG-CoA M+2 (\%) & 16.7 & 4.8 & 10.3 & 7.3 & 0.030 \\
\hline$\left.{ }^{13} \mathrm{C}_{6}\right]$-glucose & $\beta$ HB-CoA M+2 (\%) & 14.9 & 2.2 & 21.6 & 4.4 & $<0.001$ \\
& $\beta$ HB-CoA M+4 (\%) & 18.9 & 6.1 & 18.5 & 6.9 & 0.880 \\
& HMG-CoA M+2 (\%) & 23.4 & 4.9 & 29.8 & 12.8 & 0.150 \\
& HMG-CoA M+4 (\%) & 4.8 & 2.6 & 13.3 & 4.9 & $<0.001$ \\
\hline$\beta$ HB: $\beta$-hydroxybutyryl; FRDA: Friedreich's ataxia; HMG: 3-hydroxy-3-methylglutaryl; NA: Not applicable. & & \\
\hline
\end{tabular}




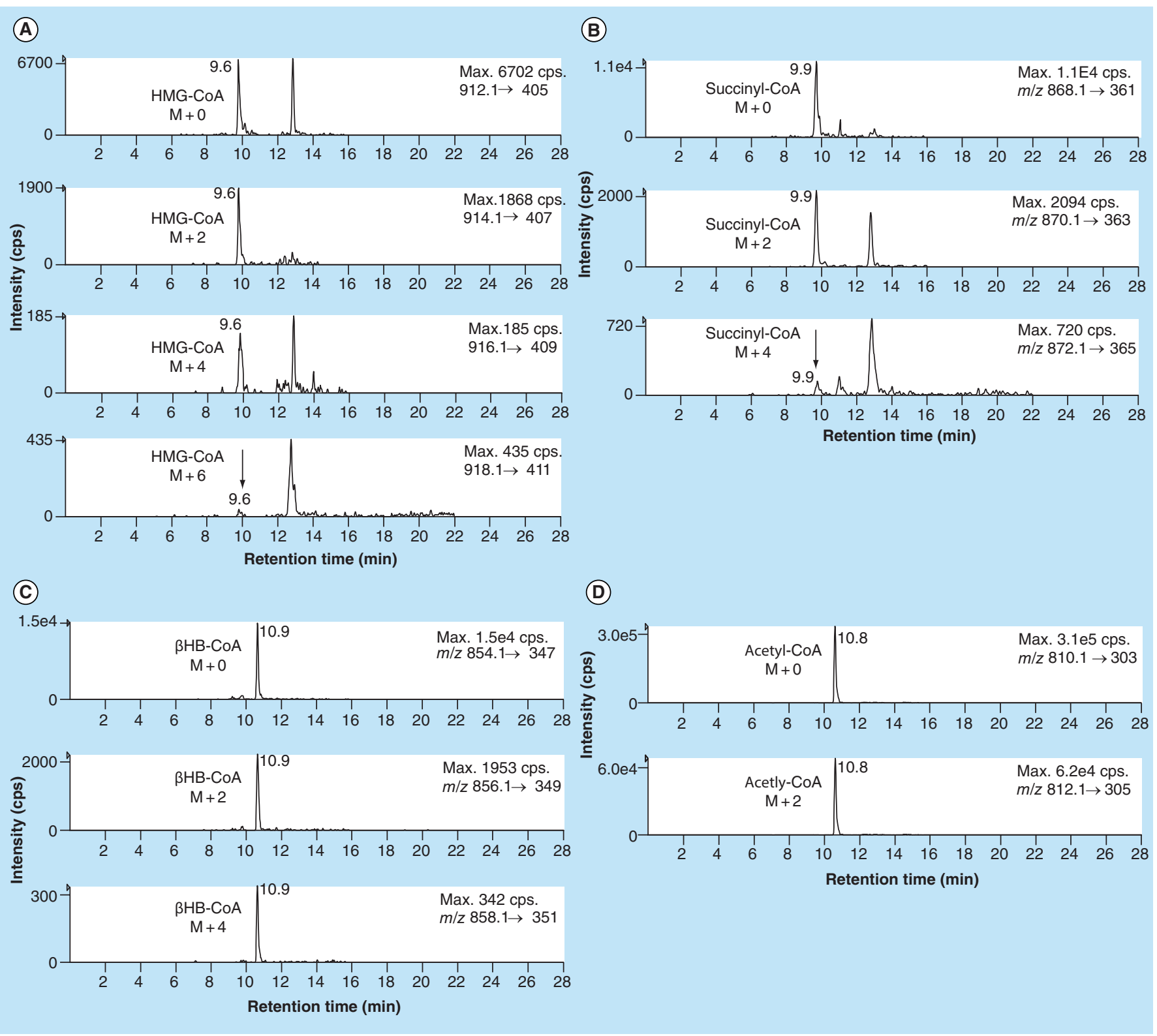

Figure 3. Representative chromatograms of the acyl-CoA thioesters analyzed in this study after incubating normal platelets with $5.5 \mathrm{mM}\left[{ }^{13} C_{5}\right]$-glucose. (A) HMG-CoA $M+0, M+2, M+4$, and $M+6$. (B) Succinyl-CoA $M+0, M+2$ and $M+4$. (C) $\beta H B-C o A M+0, M+$ 2 , and $M+4$. (D) Acetyl-CoA $M+0$ and $M+2$.

$\beta$ HB: $\beta$-Hydroxybutyryl; HMG: 3-Hydroxy-3-methylglutaryl.

would be more readily labeled due to the lower concentration of unlabeled metabolite. $M+2$ labeling in FRDA platelets from $\left[{ }^{13} \mathrm{C}_{6}\right]$-glucose for both $\beta \mathrm{HB}$ $\mathrm{CoA}(5.1 \pm 2.4 \% ; \mathrm{p}<0.01)$ and HMG-CoA $(10.3 \pm$ $7.3 \%$; $\mathrm{p}<0.05)$ was significantly lower than the $\mathrm{M}+2$ labeling of $\beta \mathrm{HB}-\mathrm{CoA}(8.5 \pm 2.9 \%)$ and $\mathrm{HMG}-\mathrm{CoA}$ $(16.7 \pm 4.8 \%)$ in control platelets (Figure $4 \mathrm{C}-\mathrm{E}$ ).

\section{Palmitate labeling}

To determine if fatty acid metabolism is affected in FRDA, platelets were treated with $100 \mu \mathrm{M}\left[{ }^{13} \mathrm{C}_{16}\right]$ palmitate for $1 \mathrm{~h}$ (Figure 1). This also made it possible to monitor the butyryl-CoA pathway for the formation of $\mathrm{M}+4$ isotopologues of $\beta \mathrm{HB}-\mathrm{CoA}$ and HMGCoA (Figure 2). Analysis of $\left[{ }^{13} \mathrm{C}\right]$-isotopic enrichment in acyl-CoAs revealed that labeling from $\left[{ }^{13} \mathrm{C}_{16}\right]$ palmitate into the Krebs cycle occurred as we had shown previously [24]. In control platelets, the $M+2$ incorporation into acetyl-CoA was $22.0 \pm 6.0 \%$ and for succinyl-CoA was $20.6 \pm 6.3 \%$. However, unlike incorporation from $\left[{ }^{13} \mathrm{C}_{6}\right]$-glucose into these Krebs cycle acyl-CoA thioesters there was no significant difference in incorporation of $\left[{ }^{13} \mathrm{C}_{16}\right]$-palmitate between FRDA and control platelets (data not shown). Direct 
thiolase-mediated formation of HMG-CoA from acetyl-CoA (Figure 2) resulted in substantial incorporation of $\left[{ }^{13} \mathrm{C}_{16}\right]$-palmitate into $\mathrm{M}+2$ for both $\beta \mathrm{HB}$ $\mathrm{CoA}(14.9 \pm 2.2 \%)$ and HMG-CoA $(23.4 \pm 4.9 \%)$ in control platelets (Figure 5A \& B). In contrast to the $\left[{ }^{13} \mathrm{C}_{6}\right]$-glucose results, there was a significant increase rather than a decrease in $\mathrm{M}+2$ labeling from $\left[{ }^{13} \mathrm{C}_{16}\right]-$ palmitate for $\beta \mathrm{HB}-\mathrm{CoA}(21.6 \pm 4.4 \%$; $<0.001)$ compared with controls (Figure 5A \& C). There was also increased incorporation of $\left[{ }^{13} \mathrm{C}_{16}\right]$-palmitate into $\mathrm{M}+2$ of HMG-CoA $(29.8 \pm 12.8 \%)$, although this did not reach statistical significance when compared with controls $(23.4 \pm 4.9 \%)$ (Figure 5B). There was also significant incorporation of $\left[{ }^{13} \mathrm{C}_{16}\right]$-palmitate into $\mathrm{M}+4$ of $\beta \mathrm{HB}-\mathrm{CoA}(18.5 \pm 6.9 \%)$ and $\mathrm{HMG}-\mathrm{CoA}(4.8 \pm 2.6 \%)$ in control platelets (Figure $5 \mathrm{~B} \& \mathrm{C}$ ), through the second
(A)

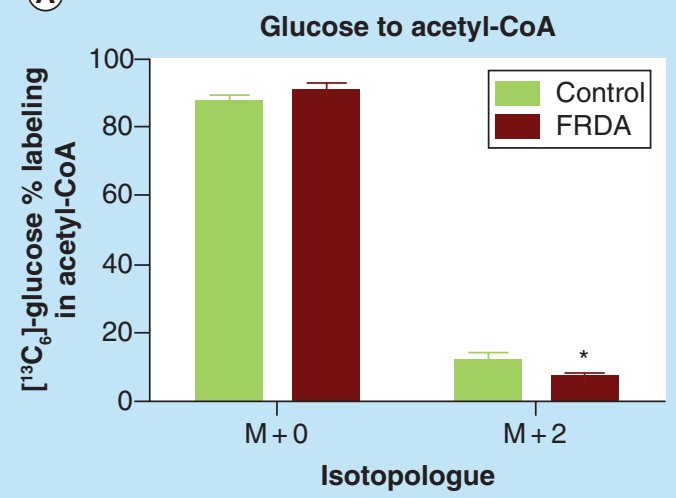

(C)

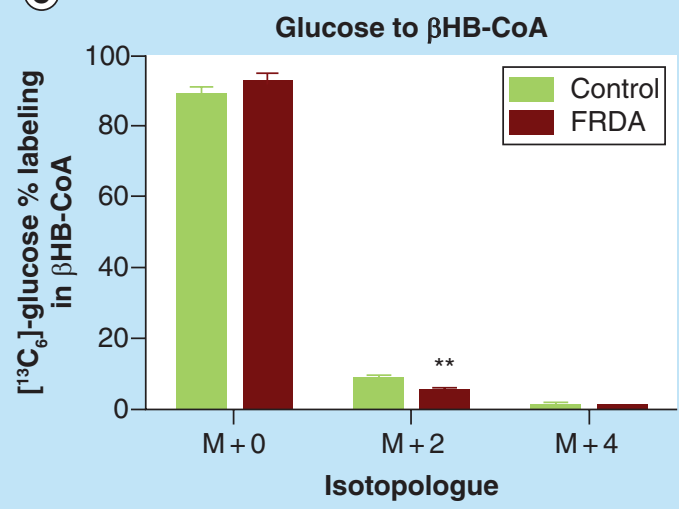

(B)
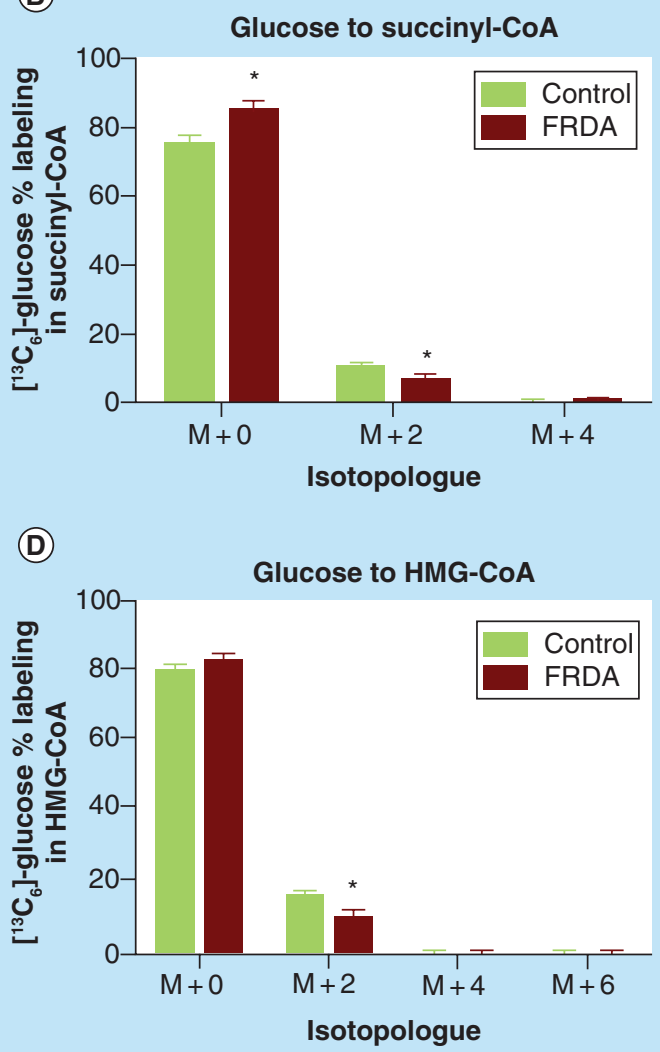

(E)

$\left[{ }^{13} \mathrm{C}_{6}\right]$-glucose labeling

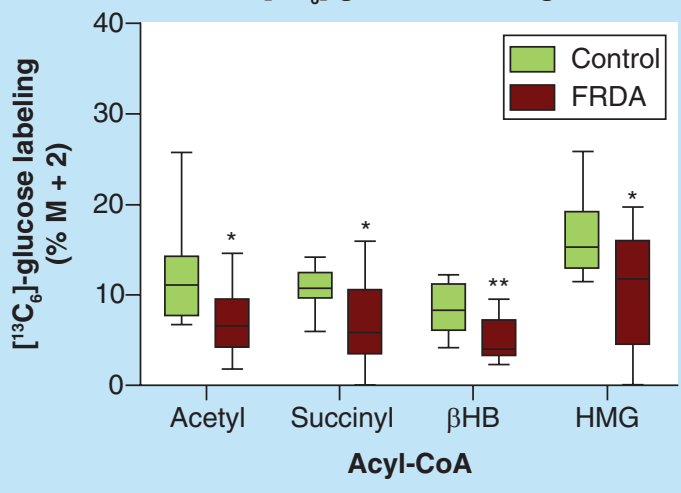

Figure 4. $\left[{ }^{13} \mathrm{C}_{6}\right]$-glucose labeling was decreased in Friedreich's ataxia platelets. (A) Acetyl-CoA. (B) Succinyl-CoA. (C) $\beta$ HB-COA. (D) HMG-COA. (E) Boxplots depicting significantly different enrichments from glucose. Mean percent labeling plotted with $S D,{ }^{*} p<0.05$ for ten patients with FRDA and ten controls (students unpaired t-test). $\beta$ HB: $\beta$-hydroxybutyryl; FRDA: Friedreich's ataxia; HMG: 3-hydroxy-3-methylglutaryl. 
(A)

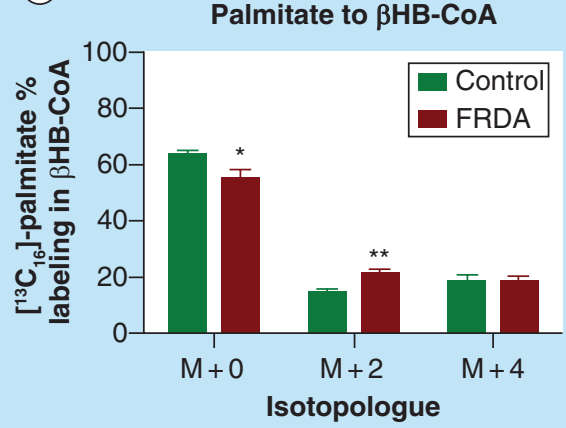

(B)

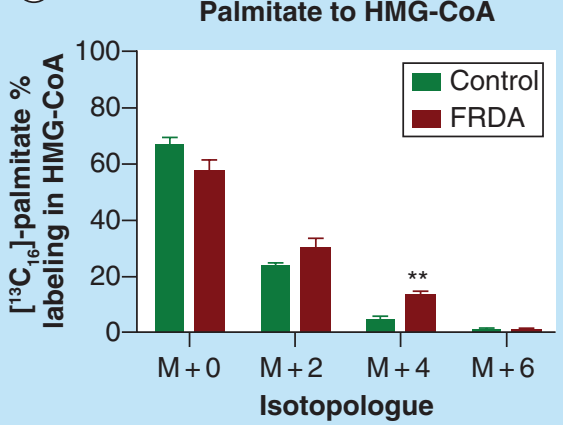

(C)

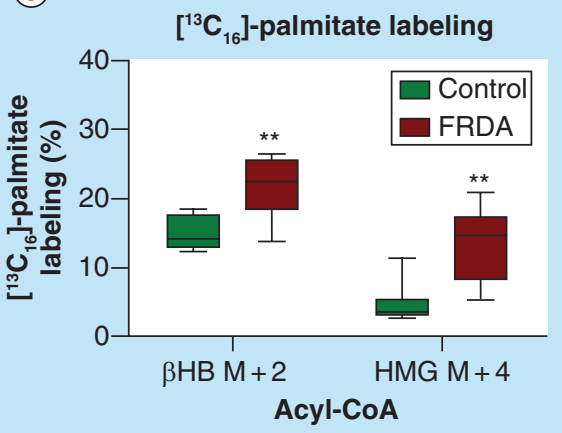

Figure 5. $\left[{ }^{13} \mathrm{C}_{16}\right]$-palmitate labeling was increased in Friedreich's ataxia platelets. (A) $\beta$ HB-CoA. (B) HMG-CoA. (C) Boxplots depicting significantly different enrichments from palmitate. Mean percent labeling plotted with $S D, * p<0.05, * * p<0.001$ for ten patients with FRDA and ten controls (students unpaired t-test).

$\beta H B$ : $\beta$-hydroxybutyryl; FRDA: Friedreich's ataxia; HMG: 3-hydroxy-3-methylglutaryl.

pathway involving intermediate formation of $\left[{ }^{13} \mathrm{C}_{4}\right]-$ butyryl-CoA (Figure 2). Interestingly, incorporation of $\left[{ }^{13} \mathrm{C}_{16}\right]$-palmitate into $\mathrm{M}+4$ for HMG-CoA in FRDA platelets $(13.3 \pm 4.9 \% ; \mathrm{p}<0.001)$ was significantly increased when compared with controls $(4.8 \pm 2.6 \%)$ (Figure 5B \& C). However, the incorporation of $\left[{ }^{13} \mathrm{C}_{16}\right]-$ palmitate into $\mathrm{M}+4$ of $\beta \mathrm{HB}-\mathrm{CoA}$ in FRDA platelets $(18.5 \pm 6.9 \%)$ was almost identical with that observed for controls (Figure 5A). This unexpected finding suggests that there is compartmentalization of some of the metabolites and that the pool sizes of these individual compartments dictate the actual incorporation.

\section{Correlation with GAA repeat length}

The decrease in $\mathrm{M}+2$ acetyl-CoA labeling from $\left[{ }^{13} \mathrm{C}_{6}\right]-$ glucose in FRDA platelets showed a negative correlation $\left(r^{2}=0.39 ; r=-0.625 ; \mathrm{p}=0.054\right)$ with GAA repeat

(A)

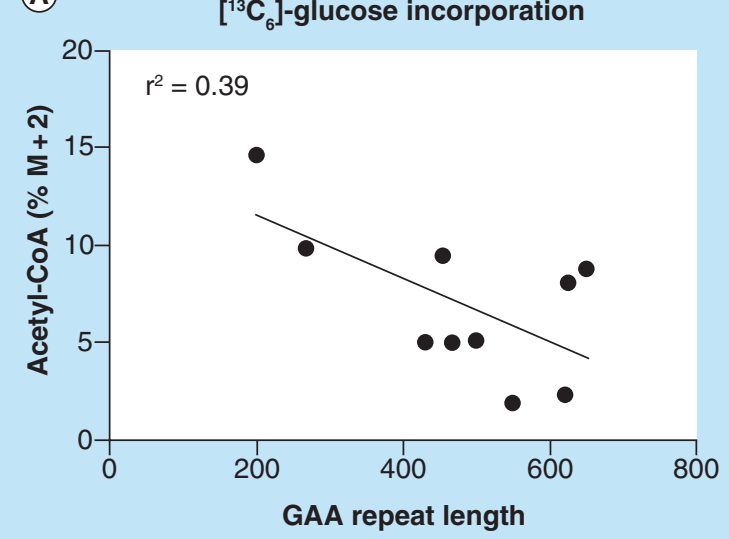

length (Figure 6A), a genetic marker of disease severity for FRDA [37]. Analogously, the increased labeling into $\beta \mathrm{HB}-\mathrm{CoA}(\mathrm{M}+2)$ from $\left[{ }^{13} \mathrm{C}_{16}\right]$-palmitate demonstrated a positive correlation $\left(\mathrm{r}^{2}=0.51 ; \mathrm{r}=0.717\right.$; $\mathrm{p}=0.020$ ) with GAA repeat length (Figure $6 \mathrm{~B}$ ). Importantly, neither of these markers correlated with patient age (data not shown).

\section{Sensitivity \& specificity}

Generation of a ROC curve by combining decreased $\mathrm{M}$ +2 labeling into acetyl-CoA from $\left[{ }^{13} \mathrm{C}_{6}\right]$-glucose and increased $\mathrm{M}+2$ labeling into $\beta \mathrm{HB}-\mathrm{CoA}$ from $\left[{ }^{13} \mathrm{C}_{16}\right]-$ palmitate revealed an AUC of 0.89 (95\% CI: 0.73-1.00) (Figure 7). This combination of biomarkers gave high sensitivity and specificity (> 80\%) under a wide range of scenarios as a result of the precision and accuracy with which the isotopologue analyses could be conducted. A

(B) $\left[{ }^{13} \mathrm{C}_{16}\right]$-palmitate incorporation

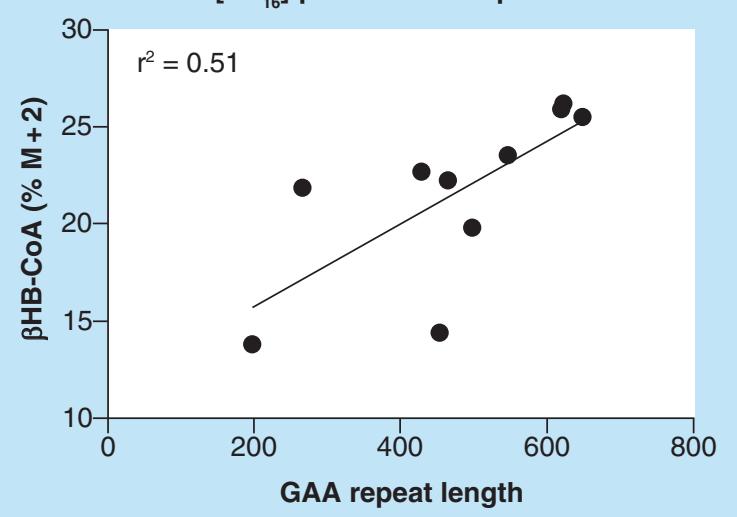

Figure 6. Triplicate guanine-adenine-adenine nucleotide repeat length correlated with labeling patterns in Friedreich's ataxia platelets. (A) Increased repeat length is negatively correlated with percent $M+2$ labeling of acetyl-CoA from $\left[{ }^{13} \mathrm{C}_{6}\right]$-glucose $(r=-0.625, p=0.054)$. (B) Increased repeat length is positively correlated with percent $\mathrm{M}+2$ labeling of $\beta \mathrm{HB}-\mathrm{CoA}$ from $\left[{ }^{13} \mathrm{C}_{16}\right]$-palmitate $(r=0.7172, \mathrm{p}=0.020)$.

$\beta$ HB: $\beta$-hydroxybutyryl; FRDA: Friedreich's ataxia. 
sensitivity of $80 \%$ and specificity of $100 \%$ were observed at the optimal cut-off value for the current samples. These data provide confidence that the methodology will provide a useful biomarker reflecting the biochemical abnormalities of FRDA and the potential response of dysfunctional metabolic pathways to therapy.

\section{Discussion}

In the present study, we have shown that FRDA platelets exhibit differential mitochondrial metabolism when compared with healthy controls. Many biomarker studies focus on absolute quantification of analytes to monitor phenotypic differences. A critical shortcoming of such approaches is the need for external normalization, which often introduces a significant degree of variability. While LC-MS analysis utilizing stable isotope internal standards controls for variability introduced during sample processing and analysis [25], either volume, cell count, protein quantity or factor normalization is required for biological normalization. Isotopologue analysis of samples treated with isotopic tracers circumvents the need for external standardization because the relative levels of isotopic incorporation are normalized to the total analyte signal within a given sample. Thus, the ability to conduct isotopologue assays, which do not require external normalization, simplifies the workflow and removes steps that can introduce high levels of variation. Working with isolated platelets reduces the potential of diluting the isotopic purity of a tracer by highly abundant and variable endogenous metabolites such as blood glucose. There is no evidence that $5.5 \mathrm{mM}$ glucose or $100 \mu \mathrm{m}$ palmitic acid can activate human platelets, which could have possibly confounded the metabolic studies. In addition, supplementation of human subjects with palmitic acid has no effect on platelet aggregation [38]. Furthermore, no platelet activation was observed during our $1 \mathrm{~h}$ incubations with labeled glucose or palmitate. Of note, the platelet metabolic biomarker approach is particularly relevant to promising strategies that systemically increase frataxin levels as it can provide a biomarker showing that frataxin increases are biologically active through normalization of the Krebs cycle and related metabolic pathways.

The decreased conversion of glucose to acetyl-CoA (Figure 4A) is consistent with studies that have shown diminished pyruvate oxidation in FRDA [39]. The lack of a compensatory pathway to acetyl-CoA from fatty acid $\beta$-oxidation suggests that decreased histone acetylation could occur in FRDA through decreased cofactor availability similar to our recent observation in tumor cells [40]. This finding is also consistent with epigenetic silencing of frataxin expression that occurs in FRDA [41] as a result of the GAA expansion [4,42], which results in increased DNA [43,44] and histone methylation [45] at

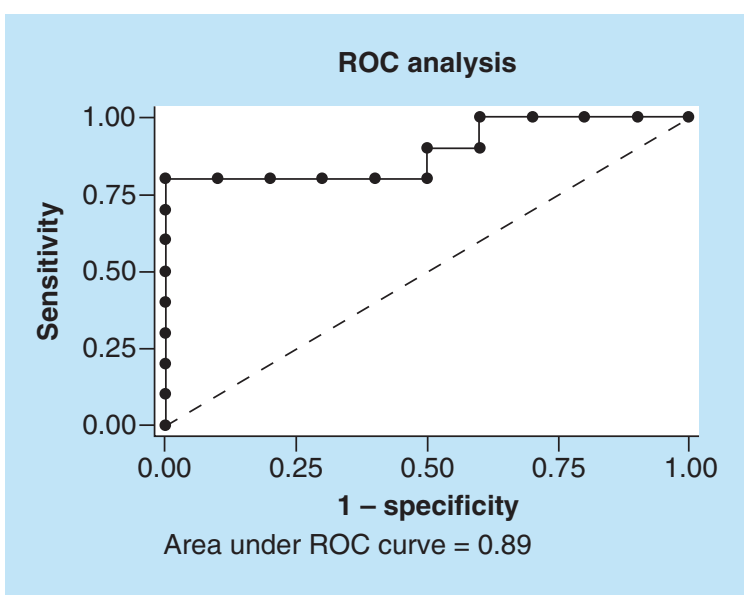

Figure 7. Receiver operating characteristic curve generated by combining the two biomarkers shown in Figure 6. Percent $M+2$ labeling of acetyl-CoA from $\left[{ }^{13} C_{6}\right]$-glucose and percent $M+2$ labeling of $\beta$-hydroxybutyryl-CoA from $\left[{ }^{13} \mathrm{C}_{16}\right]$-palmitate. The AUC is $0.89(95 \% \mathrm{Cl}: 0.73-1.00)$. The equation of the ROC curve is $41.74 \times(\% \mathrm{M}+2$ of acetyl-CoA $)-8.67 \times(\% \mathrm{M}+2$ of $\beta$-hydroxybutyryl-CoA).

ROC: Receiver operating characteristic.

the expense of histone acetylation. Decreased glucose utilization in FRDA platelets also results in decreased labeling of succinyl-CoA, suggesting that without some compensatory metabolic change there could be downregulation of protein succinylation in FRDA through decreased cofactor availability. The exact biochemical consequences of decreased protein succinylation have yet to be determined, although isocitrate dehydrogenase, an important Krebs cycle enzyme, is succinylated [46]. The decreased glucose $M+2$ labeling of acetyl-CoA in FRDA platelets (Figure 4A) also resulted in decreased incorporation of glucose into $\beta \mathrm{HB}-\mathrm{CoA}$ (Figure $5 \mathrm{~A}$ ) and HMG-CoA (Figure 5B), important intermediates in the formation of $\mathrm{D}$ - $\beta$-hydroxybutyrate (ketone body), sterols and prenylated proteins. It appears that the increased $\beta$-oxidation of fatty acids can overcome these defects but cannot compensate for the reduction in acetyl-CoA and succinyl-CoA formation. Based on our results, multiple metabolic pathways dysregulated in FRDA can be monitored using platelets from affected patients as biomarkers. Two of the isotopologue biomarkers, percent $\mathrm{M}+2$ labeling of acetyl-CoA from $\left[{ }^{13} \mathrm{C}_{6}\right]$-glucose and percent $\mathrm{M}+2$ labeling of $\beta \mathrm{HB}-\mathrm{CoA}$ from $\left[{ }^{13} \mathrm{C}_{16}\right]$-palmitate, correlated with the severity of the disease (Figure 6A \& B). Importantly, the ROC curve obtained by combining two of these biomarkers had an AUC of 0.89 (Figure 7).

The $\beta$-oxidation of fatty acids results in the removal of two carbon adjacent atoms and results in the formation of one molecule of $\mathrm{FADH}_{2}$ together with one molecule of NADH [27]. The fatty acid-derived $\mathrm{FADH}_{2}$ and NADH can then be used to maintain an electro- 


\section{Key term}

Histone deacetylase inhibitor: Acetylation of lysine residues in core histones leads to a less compact and more transcriptionally active chromatin. HDAC inhibitors block the deacetylation of histone lysine residues, which can result in increased gene expression.

chemical gradient across the inner mitochondrial membrane, which is necessary for the production of ATP. Therefore, the increased lipid metabolism observed in the FRDA could help maintain cellular homeostasis in times of mitochondrial dysfunction. Taken together, these results suggest that FRDA platelets have a diminished capacity for oxidative phosphorylation, as decreased glucose labeling into acetyl-CoA occurs in response to pharmacologic inhibition of mitochondrial complex I [26]. Cell culture studies have shown increased $\beta$-oxidation of lipids in response to diminished complex I activity [27], supporting the notion that lipid breakdown (to provide reducing equivalents) could be important during times of mitochondrial dysfunction. It is also consistent with the loss of mitochondrial complex I function that has been identified in FRDA [18]. Here, we have shown that there is a shift in metabolism toward production of $\beta \mathrm{HB}-\mathrm{CoA}$ and HMG-CoA from palmitate in FRDA platelets.

Cardiac muscle is highly dependent on fatty acids for its energy needs [47], and would therefore likely be one of the most susceptible tissues to alterations in lipid metabolism in FRDA. Cardiovascular events [1,3] are among the most serious life-limiting conditions in patients with FRDA. Therefore, pharmacologic or dietary interventions to help amend such metabolic abnormalities could have therapeutic benefits. For example, medium-chain fatty acids (MCFAs) are able to enter mitochondria independently of the carnitine shuttle system [48], making them readily available in times of metabolic stress. In addition to increased lipid oxidation, complex I inhibition also induces a dramatic decrease in medium-chain acyl-CoAs [27]. Upregulation of the medium-chain acylCoA dehydrogenase has been implicated in FRDA [49], suggesting a possible connection with MCFA metabolism. It remains to be seen if MCFAs play a defining role in energy metabolism in FRDA, as other metabolic pathways are likely influenced in FRDA.

Patients with FRDA have variable numbers of GAA repeats in intron 1 of the frataxin gene, which causes epigenetic silencing that results in decreased expression of frataxin mRNA and as well as reduced frataxin protein expression [42]. One pathway of epigenetic silencing arises through upregulation of histone lysine methyltransferases resulting in increased methylation of specific lysine residues on histone tails (e.g., H3K9) and inhibition of frataxin gene transcription [45]. Cosi- lencing of the $n r f-2$ gene in FRDA could potentially result from a similar pathway. This would then explain the paradoxical finding that nrf-2 expression is reduced in FRDA [45]. The reduction in nrf-2 protein expression in FRDA suggests that there would be a reduced ability to mount an antioxidant response. However, urinary 8-oxo-2'-deoxyguanosine [50] and isoprostane $\mathrm{F}_{2 \alpha}$ [51], which are the best validated in vivo biomarkers of oxidative stress [52,53], are indistinguishable between patients with FRDA and unaffected controls. Furthermore, the antioxidant therapies that have been tested to date have significantly improved outcomes in FRDA [54]. These findings, coupled with the reduced levels of frataxin in patients with FRDA, have stimulated an alternative strategy to overcome epigenetic silencing of the frataxin gene, which has involved the use of interferon $\gamma$, erythropoietin, nicotinamide and histone deacetylase inhibitors [2,54,55]. Consequently, methods for quantifying mitochondrial frataxin protein and mRNA expression have been developed as biomarkers to monitor these new therapeutic approaches [56,57]. Other biomarkers of FRDA to monitor the efficacy of novel therapeutic strategies, such as iron chelation with deferiprone, [58] include MRI [59], glucose tolerance [60] and ataxia rating scales with performance measures [50]. None of these likely has the sensitivity of the approaches tested here.

It is noteworthy that there are no approved treatments for FRDA, although there are drugs in preclinical and early clinical development. The lack of good biomarkers represents a bottleneck for moving these drugs forward, especially into Phase II clinical trials, for which the US FDA expects biochemical confirmation of mechanistic claims. The platelet metabolic biomarkers are helping to overcome this problem through their use in clinical trials of new drugs that are being tested as potential therapeutic agents for FRDA.

\section{Conclusion}

We have shown for the first time that the treatment of isolated platelets with isotopic tracers coupled with isotopologue analysis by LC-MS can be used to characterize metabolic alterations that are central to cellular metabolism. Such studies could not be conducted using NMR spectrometry because the low ng amounts of isotopologues formed were several orders of magnitude below that required for analyses by such methodology. Platelets from patients with FRDA exhibited metabolic abnormalities that agree with models of impaired mitochondrial function. Importantly, our findings suggest that in addition to the Krebs cycle, shifts in lipid metabolism may be an important mechanism implicated in FRDA. The biomarker methodology developed here will be useful in future studies of 
novel therapeutic agents designed to upregulate mitochondrial frataxin protein as an important complement to the protein and mRNA biomarker analyses that have already been developed.

\section{Future perspective}

The current biomarkers of FRDA, which involve the quantification of the GAA triplicate repeats in the first intron of the FRX gene or the analysis mutations in the FRX gene have essentially $100 \%$ sensitivity and specificity for detection of the disease. Therefore, new biomarkers for the early detection of FRDA are not required. However, the genetic abnormalities in FRDA cannot be modified unless gene therapy is used to increase frataxin levels. This means that the ability to examine dysregulated metabolism in FRDA patients will be extremely useful for monitoring promising therapeutic strategies that systemically increase frataxin levels. The use of platelets coupled with stable isotopes and LC-MS will provide rigorous biomarkers to show that increased frataxin protein expression stimulated by conventional therapeutic strategies (such the use of HDAC inhibitors) can reverse the mitochondrial dysregulation in FRDA. Frataxin activity will be revealed through normalization of the Krebs cycle and related metabolic pathways in the platelets. We anticipate that this will be of great benefit in clinical trials testing agents that are designed to correct the defect in frataxin protein expression. Furthermore, the concept of using platelets as metabolic biomarkers is not limited to FRDA, but may be useful for disease detection for inborn errors of metabolism as well as for other diseases of mitochondrial dysfunction. Finally, the short half-life of platelets in the circulation (typically $100 \mathrm{~h}$ ) makes it possible to evaluate biochemical effects over relatively small time scales, making this approach amenable to assessing the effectiveness of acute adaptations in response to therapeutic approaches.
Supplementary data

To view the supplementary data that accompany this paper please visit the journal website at: www.future-science.com/ doi/full/10.4155/bio.15.118

\section{Author contributions}

All authors participated in the design of the study and in analysis of the results. AJ Worth, SS Basu, EC Deutsch and NW Snyder performed the platelet incubations and conducted the LC-SRM/MS experiments. W-T Hwang designed and conducted statistical analyses. AJ Worth, DR Lynch and IA Blair. wrote the manuscript with significant input from all of the authors. All of the authors read and approved the final manuscript.

\section{Financial \& competing interests disclosure}

The authors acknowledge the support of the Penn/CHOP Friedreich's Ataxia Center of Excellence and $\mathrm{NIH}$ grants R21NS087343, P30ES013508 and T32ES019851. The authors have no other relevant affiliations or financial involvement with any organization or entity with a financial interest in or financial conflict with the subject matter or materials discussed in the manuscript apart from those disclosed.

No writing assistance was utilized in the production of this manuscript.

\section{Ethical conduct of research}

The authors state that they have obtained appropriate institutional review board approval or have followed the principles outlined in the Declaration of Helsinki for all human or animal experimental investigations. In addition, for investigations involving human subjects, informed consent has been obtained from the participants involved.

\section{Open access}

This work is licensed under the Creative Commons Attribution-NonCommercial 3.0 Unported License. To view a copy of this license, visit http://creativecommons.org/licenses/bync-nd/3.0/

\section{Executive summary}

\section{Materials \& methods}

- Platelets from Friedreich's ataxia (FRDA) patients and healthy volunteers were isolated from whole blood and incubated with two $\left[{ }^{13} \mathrm{C}\right]$-labeled metabolic tracers $-\left[{ }^{13} \mathrm{C}_{6}\right]$-glucose and $\left[{ }^{13} \mathrm{C}_{16}\right]$-palmitate.

- The incorporation $\left[{ }^{13} \mathrm{C}\right]$-atoms into different platelet-derived short chain acyl-CoA thioesters isotopologues was determined.

Results

- Isotopologue analysis of acyl-CoA thioesters by LC-MS revealed a marked decrease in glucose incorporation into acyl-CoA thioesters in FRDA platelets compared with controls.

- There was concomitant increase in palmitate-derived acyl-CoA thioester isotopologues.

- The findings were consistent with a combination of decreased glycolysis and increased fatty acid $\beta$-oxidation known to occur in FRDA.

- Human platelets served as a surrogate tissue for in vivo biomarker studies.

Future perspective

- Human platelets coupled with stable isotopes and LC-MS will provide rigorous biomarkers that will be useful for monitoring new therapeutic approaches for the treatment of FRDA. 


\section{References}

1 Delatycki MB, Williamson R, Forrest SM. Friedreich ataxia: an overview. J. Med. Genet. 37(1), 1-8 (2000).

2 Lynch DR, Seyer L. Friedreich Ataxia: new findings, new challenges. Ann. Neurol. 76(4), 487-488 (2014).

3 Darius JR, Michael LHH, Samantha T, Sutharshani S, Des R. Biochemistry of cardiomyopathy in the mitochondrial disease Friedreich's ataxia. Biochem. J. 453(3), 321-336 (2013).

4 De BI, Rasmussen A, Endres D et al. Progressive GAA expansions in dorsal root ganglia of Friedreich's ataxia patients. Ann. Neurol. 61(1), 55-60 (2007).

5 Palau F. Friedreich's ataxia and frataxin: molecular genetics, evolution and pathogenesis. Int. J. Mol. Med. 7(6), 581-589 (2001).

6 Gellera C, Castellotti B, Mariotti C et al. Frataxin gene point mutations in Italian Friedreich ataxia patients. Neurogenetics 8(4), 289-299 (2007).

7 Bartolo C, Mendell JR, Prior TW. Identification of a missense mutation in a Friedreich's ataxia patient: implications for diagnosis and carrier studies. Am. J. Med. Genet. 79(5), 396-399 (1998).

8 Cossee M, Durr A, Schmitt M et al. Friedreich's ataxia: point mutations and clinical presentation of compound heterozygotes. Ann. Neurol. 45(2), 200-206 (1999).

9 Bidichandani SI, Ashizawa T, Patel PI. Atypical Friedreich ataxia caused by compound heterozygosity for a novel missense mutation and the GAA triplet-repeat expansion. Am. J. Hum. Genet. 60(5), 1251-1256 (1997).

10 Forrest SM, Knight M, Delatycki MB et al. The correlation of clinical phenotype in Friedreich ataxia with the site of point mutations in the FRDA gene. Neurogenetics 1(4), 253-257 (1998).

11 Al-Mahdawi S, Pook M, Chamberlain S. A novel missense mutation (L198R) in the Friedreich's ataxia gene. Hum. Mutat. 16(1), 95 (2000).

12 Cavadini P, Adamec J, Taroni F, Gakh O, Isaya G. Two-step processing of human frataxin by mitochondrial processing peptidase. Precursor and intermediate forms are cleaved at different rates. J. Biol. Chem. 275(52), 41469-41475 (2000).

13 Schmucker S, Argentini M, Carelle-Calmels N, Martelli A, Puccio $\mathrm{H}$. The in vivo mitochondrial two-step maturation of human frataxin. Hum. Mol. Genet. 17(22), 3521-3531 (2008).

14 Marmolino D. Friedreich's ataxia: past, present and future. Brain Res. Rev. 67(1-2), 311-330 (2011).

15 Parkinson MH, Boesch S, Nachbauer W, Mariotti C, Giunti P. Clinical features of Friedreich's ataxia: classical and atypical phenotypes. J. Neurochem. 126(Suppl. 1), 103-117 (2013).

16 Li H, Gakh O, Smith DY, Ranatunga WK, Isaya G. Missense mutations linked to friedreich ataxia have different but synergistic effects on mitochondrial frataxin isoforms. J. Biol. Chem. 288(6), 4116-4127 (2013).

17 Stehling O, Lill R. The role of mitochondria in cellular ironsulfur protein biogenesis: mechanisms, connected processes, and diseases. Cold. Spring. Harb. Perspect. Biol. 5(8), 1-17 (2013).

18 Rötig A, de Lonlay P, Chretien D et al. Aconitase and mitochondrial iron-sulphur protein deficiency in Friedreich ataxia. Nat. Genet. 17(2), 215-217 (1997).

19 Calabrese V, Lodi R, Tonon C et al. Oxidative stress, mitochondrial dysfunction and cellular stress response in Friedreich's ataxia. J. Neurol. Sci. 233(1), 145-162 (2005).

20 Isaya G. Mitochondrial iron-sulfur cluster dysfunction in neurodegenerative disease. Front. Pharmacol. 5), 1-7 (2014).

21 Lodi R, Hart PE, Rajagopalan B et al. Antioxidant treatment improves in vivo cardiac and skeletal muscle bioenergetics in patients with Friedreich's ataxia. Ann. Neurol. 49(5), 590-596 (2001).

22 Jauslin ML, Meier T, Smith RA, Murphy MP. Mitochondria-targeted antioxidants protect Friedreich ataxia fibroblasts from endogenous oxidative stress more effectively than untargeted antioxidants. FASEB J. 17(13), 1972-1974 (2003).

23 Bogan KL, Brenner C. Nicotinic acid, nicotinamide, and nicotinamide riboside: a molecular evaluation of NAD + precursor vitamins in human nutrition. Annu. Rev. Nutr. 28), 115-130 (2008).

24 Basu SS, Deutsch EC, Schmaier AA, Lynch DR, Blair IA. Human platelets as a platform to monitor metabolic biomarkers using stable isotopes and LC-MS. Bioanalysis 5(4), 3009-3021 (2013).

25 Ciccimaro E, Blair IA. Stable-isotope dilution LC-MS for quantitative biomarker analysis. Bioanalysis 2(2), 311-341 (2010).

26 Basu SS, Blair IA. Rotenone-mediated changes in intracellular coenzyme A thioester levels: implications for mitochondrial dysfunction. Chem. Res. Toxicol. 24(10), 1630-1632 (2011).

27 Worth AJ, Basu SS, Snyder NW, Mesaros C, Blair IA. Inhibition of neuronal cell mitochondrial complex I with rotenone increases lipid $\beta$-oxidation supporting acetylcoenzyme A levels. J. Biol. Chem. 289), 26895-26903 (2014).

28 Zhang GF, Sadhukhan S, Tochtrop GP, Brunengraber H. Metabolomics, pathway regulation, and pathway discovery. J. Biol. Chem. 286(27), 23631-23635 (2011).

29 Bequette BJ, Sunny NE, El-Kadi SW, Owens SL. Application of stable isotopes and mass isotopomer distribution analysis to the study of intermediary metabolism of nutrients. J. Anim. Sci. 84(13 Suppl.), E50-E59 (2006).

30 Maurer-Spurej E, Pittendreigh C, Solomons K. The influence of selective serotonin reuptake inhibitors on human platelet serotonin. Thromb. Haemost. 91(1), 119-128 (2004).

31 Ferrarese C, Zoia C, Pecora N et al. Reduced platelet glutamate uptake in Parkinson's disease. J. Neural. Transm. 106(7-8), 685-692 (1999).

32 Zharikov $S$, Shiva S. Platelet mitochondrial function: from regulation of thrombosis to biomarker of disease. Biochem. Soc. Trans. 41(1), 118-123 (2013).

33 Snyder NW, Basu SS, Worth AJ, Mesaros C, Blair IA. Metabolism of propionic acid to a novel acyl-coenzyme A 
thioester by mammalian cell lines and platelets. J. Lipid Res. 56(1), 142-150 (2015). isotopically labeled coenzyme A mass spectrometry standards. Nat. Protoc. 7(1), 1-12 (2012).

35 Fernandez CA, Des Rosiers C, Previs SF, David F, Brunengraber $\mathrm{H}$. Correction of $13 \mathrm{C}$ mass isotopomer distributions for natural stable isotope abundance. J. Mass Spectrom. 31(3), 255-262 (1996).

Buescher JM, Antoniewicz MR, Boros LG et al. A roadmap for interpreting $\mathrm{C}$ metabolite labeling patterns from cells. Curr. Opin. Biotechnol. 34), 189-201 (2015).

37 Filla A, De Michele G, Cavalcanti F et al. The relationship between trinucleotide (GAA) repeat length and clinical features in Friedreich ataxia. Am. J. Hum. Genet. 59(3), 554-560 (1996).

38 Sanchez-Muniz FJ, Oubina P, Rodenas S, Benedi J, Cuesta C. Platelet aggregation, thromboxane production and thrombogenic ratio in postmenopausal women consuming high oleic acid-sunflower oil or palmolein. Eur. J. Nutr. 42(6), 299-306 (2003).

39 Kark R, Blass JP, Engel W. Pyruvate oxidation in neuromuscular diseases: evidence of a genetic defect in two families with the clinical syndrome of Friedreich's ataxia. Neurology 24(10), 964-971 (1974).

40 Lee JV, Carrer A, Shah S et al. Akt-dependent metabolic reprogramming regulates tumor cell histone acetylation. Cell Metab. 20(2), 306-319 (2014).

41 Soragni E, Miao W, Iudicello M et al. Epigenetic therapy for Friedreich ataxia. Ann. Neurol. 76(4), 489-508 (2014).

42 Kim E, Napierala M, Dent SY. Hyperexpansion of GAA repeats affects post-initiation steps of $F X N$ transcription in Friedreich's ataxia. Nucleic Acids Res. 39(19), 8366-8377 (2011).

43 Evans-Galea MV, Carrodus N, Rowley SM et al. FXN methylation predicts expression and clinical outcome in Friedreich ataxia. Ann. Neurol. 71(4), 487-497 (2012).

44 Chutake YK, Lam C, Costello WN, Anderson M, Bidichandani SI. Epigenetic promoter silencing in Friedreich ataxia is dependent on repeat length. Ann. Neurol. 76(4), 522-528 (2014)

45 Sahdeo S, Scott BD, McMackin MZ et al. Dyclonine rescues frataxin deficiency in animal models and buccal cells of patients with Friedreich's ataxia. Hum. Mol. Genet. 23(25), 6848-6862 (2014).

Zhang Z, Tan M, Xie Z, Dai L, Chen Y, Zhao Y. Identification of lysine succinylation as a new post-translational modification. Nat. Chem. Biol. 7(1), 58-63 (2011).

47 Stanley WC, Recchia FA, Lopaschuk GD. Myocardial substrate metabolism in the normal and failing heart. Physiol. Rev. 85(3), 1093-1129 (2005).
48 Papamandjaris AA, MacDougall DE, Jones PJ. Medium chain fatty acid metabolism and energy expenditure: obesity treatment implications. Life. Sci. 62(14), 1203-1215 (1998).

49 Obis È, Irazusta V, Sanchís D, Ros J, Tamarit J. Frataxin deficiency in neonatal rat ventricular myocytes targets mitochondria and lipid metabolism. Free Radical. Bio. Med. 73, 21-33 (2014).

50 Di Prospero NA, Baker A, Jeffries N, Fischbeck KH. Neurological effects of high-dose idebenone in patients with Friedreich's ataxia: a randomised, placebo-controlled trial. Lancet Neurol. 6(10), 878-886 (2007).

51 Myers LM, Lynch DR, Farmer JM, Friedman LS, Lawson JA, Wilson RB. Urinary isoprostanes in Friedreich ataxia: lack of correlation with disease features. Mov. Disord. 23(13), 1920-1922 (2008).

52 Kadiiska MB, Gladen BC, Baird DD et al. Biomarkers of oxidative stress study II: are oxidation products of lipids, proteins, and DNA markers of $\mathrm{CCl}_{4}$ poisoning? Free Radic. Biol. Med. 38(6), 698-710 (2005).

53 Mesaros C, Arora JS, Wholer A, Vachani A, Blair IA. 8-Oxo-2'-deoxyguanosine as a biomarker of tobaccosmoking-induced oxidative stress. Free Radic. Biol. Med. 53(3), 610-617 (2012).

54 Strawser CJ, Schadt KA, Lynch DR. Therapeutic approaches for the treatment of Friedreich's ataxia. Expert Rev. Neurother. 14(8), 949-957 (2014).

55 Boesch S, Sturm B, Hering S, Goldenberg H, Poewe W, Scheiber-Mojdehkar B. Friedreich's ataxia: clinical pilot trial with recombinant human erythropoietin. Ann. Neurol. 62(5), 521-524 (2007).

56 Plasterer HL, Deutsch EC, Belmonte M, Egan E, Lynch DR, Rusche JR. Development of frataxin gene expression measures for the evaluation of experimental treatments in Friedreich's ataxia. PLoS ONE 8(5), e63958 (2013).

57 Deutsch EC, Oglesbee D, Greeley NR, Lynch DR. Usefulness of frataxin immunoassays for the diagnosis of Friedreich ataxia. J. Neurol. Neurosurg. Psychiatry 85(9), 994-1002 (2014).

58 Pandolfo M, Arpa J, Delatycki MB et al. Deferiprone in Friedreich ataxia: a 6-month randomized controlled trial. Ann. Neurol. 76(4), 509-521 (2014).

59 Santner W, Schocke M, Boesch S, Nachbauer W, Egger K. A longitudinal VBM study monitoring treatment with erythropoietin in patients with Friedreich ataxia. Acta Radiol. Short Rep. 3(4), 2047981614531573 (2014).

60 Hebinck J, Hardt C, Schols L et al. Heterozygous expansion of the GAA tract of the X25/frataxin gene is associated with insulin resistance in humans. Diabetes 49(9), 1604-1607 (2000). 